\title{
Structural and chemical evolution of single-wall carbon nanotubes under atomic and molecular deuterium interaction
}

\author{
W. Lisowski ${ }^{a, *}$, E.G. Keim ${ }^{\text {b,* }}$, A.H.J. van den Berg ${ }^{\text {b }}$, M.A. Smithers ${ }^{b}$ \\ ${ }^{a}$ Institute of Physical Chemistry, Polish Academy of Sciences, Kasprzaka 44/52, PL-01-224 Warszawa, Poland \\ ${ }^{\mathrm{b}} \mathrm{MESA}^{+}$Research Institute, Central Materials Analysis Laboratory, University of Twente, P. O. Box 217, 7500 AE Enschede, The Netherlands
}

Received 22 September 2004; accepted 3 December 2004

Available online 18 January 2005

\begin{abstract}
The interaction of atomic (D) and molecular $\left(\mathrm{D}_{2}\right)$ deuterium, as present in a $\left(\mathrm{D}+\mathrm{D}_{2}\right)$ gas mixture, with single-wall carbon nanotubes (SWNTs) has been studied by means of a combination of scanning electron microscopy, transmission electron microscopy and X-ray photoelectron spectroscopy. The SWNT samples were exposed to the gas mixture, produced by thermal dissociation of $\mathrm{D}_{2}$ on a hot $\mathrm{W}$ filament, its temperature, $T_{\mathrm{W}}$, being kept at 1020 and $1550 \mathrm{~K}$ for a deuterium pressure of 0.6 and $60 \mathrm{~Pa}$, respectively. Prolonged interaction of the low-pressure $\left(\mathrm{D}+\mathrm{D}_{2}\right)$ gas mixture produced at $T_{\mathrm{W}}=1020 \mathrm{~K}$ leads to a conglomeration of the SWNT bundles into larger diameter ropes of square and triangular cross-section, covered by nanoaggregates of graphite material. Both the coalescence of single SWNTs and a massive reconstruction of bundles of SWNTs into a "coral reef"-like structure were found to occur after prolonged exposure of SWNTs to the high-pressure $\left(\mathrm{D}+\mathrm{D}_{2}\right)$ gas mixture produced at $T_{\mathrm{W}}=1550 \mathrm{~K}$. This structure is formed by the encapsulated Fe nanoparticles and deuterocarbon-like species appearing as a result of the deuterium interaction with the SWNT bundles accompanied by partial erosion of the SWNT material. The XPS valence-band spectra disclose electronic features characteristic for a hydrogen-plasma modified multi-wall carbon nanotube (MWNT)-like structure as a result of an intensive $\left(D+D_{2}\right)$ induced transformation of the SWNTs into the "coral reef"-like structure.

(c) 2004 Elsevier Ltd. All rights reserved.
\end{abstract}

Keywords: Carbon nanotubes; Scanning electron microscopy, Transmission electron microscopy, X-ray photoelectron spectroscopy; Microstructure

\section{Introduction}

Hydrogen (deuterium) interaction with single-wall carbon nanotubes (SWNTs) has attracted much theoretical and experimental interest recently [1-19]. One of the main reasons for this interest was due to the possibility of using SWNTs for hydrogen storage. However, the promising considerable storage capacity of hydrogen in SWNTs, reported by some authors

\footnotetext{
* Corresponding authors. Tel.: +31 534895 915; fax: +31 534894 274 (E.G. Keim).

E-mail addresses: wlis@ichf.edu.pl (W. Lisowski), e.g.keim@tnw. utwente.nl (E.G. Keim).
}

$[2,3]$, has still not been experimentally confirmed, as reported by independent groups of scientists [13-15]. Nevertheless, several important observations with regard to hydrogen (deuterium) interaction as well as hydrogen (deuterium) induced transformation of carbon nanostructures have been made. The results are interesting for many scientific and technological applications such as semiconductor technology, catalysis, astrophysics and fusion plasma physics; to summarize:

- Two kinds of interaction can occur between hydrogen (deuterium) and SWNTs [1,6,9,18]: molecular physisorption inside and outside the nanotube as well as 
chemisorption of hydrogen (deuterium) atoms. The molecularly adsorbed hydrogen (deuterium) species are weakly adsorbed (binding energy lower than $0.1 \mathrm{eV}[1,6,12])$ whereas the dissociatively adsorbed hydrogen (deuterium) forms covalent $\mathrm{C}-\mathrm{H}(\mathrm{C}-\mathrm{D})$ species (binding energy more than $2-3 \mathrm{eV}[1,10,18]$ ). Dillon et al. [19] also identified an intermediate state between the physi- and chemisorption of hydrogen, which was also considered to be suitable for hydrogen storage.

- The electronic and atomic structure of SWNTs undergo dramatic changes with hydrogen chemisorption as shown from first principles total energy and electronic structure calculations $[5,18]$. Upon hydrogenation the structure of SWNTs undergoes a massive reconstruction and the newly formed structures appearing are stabilized by the formation of new diamond-like $\mathrm{C}-\mathrm{C}$ bonds [5].

- The complex character of energetic hydrogen interaction with SWNTs has been dealt using a molecular dynamics simulations method [16,17]. In the incident energy interval 1-3 eV the hydrogen atoms chemisorb onto the outer wall of the SWNTs, forming an exohedral H-tube complex [16]. The reaction barrier for $\mathrm{H}$ chemisorption on an undistorted perfect nanotube was estimated to be about $1 \mathrm{eV}$ [16], whereas the corresponding value calculated for a torsion strained nanotube was found to be small compared to $\mathrm{kT}$ at $300 \mathrm{~K}[20]$.

- High-temperature thermal treatments have a strong influence on the structural and microtextural characteristics of SWNTs [21-23]. Coalescence of SWNTs annealed at temperatures of $1673-2273 \mathrm{~K}$ in the presence of $\mathrm{Ar}$ [21-23] and $\mathrm{H}_{2}$ [21] has been observed. At temperatures above $2273 \mathrm{~K}$ bundles of SWNTs coalesce forming multi-wall carbon nanotubes (MWNTs). The process of this structural evolution has been computer-simulated [23].

- It is still unclear as to what the influence of residual $\mathrm{Fe}$, used as a catalyst in the production of SWNTs, is on the structure of the SWNTs. The Fe impurities were considered to affect the thermal coalescence of SWNTs through defects introduced by a chemical modification in the SWNTs [24]. However, in a recently published report [25] it was shown that similar thermally induced changes of the structure of SWNTs can occur without a metal catalyst.

In this work our interest is focused primarily on the structural and chemical modification of SWNTs after prolonged interaction with a mixture of molecular $\left(D_{2}\right)$ and atomic (D) deuterium gas. This subject has stimulated growing interest lately [5,18], although experimental activity is still rather low. The major issue is to how the atomic and molecular deuterium treatment will affect the structural and chemical evolution of SWNTs at different temperatures. In order to elucidate this point we used the combination of X-ray photoelectron spectroscopy (XPS), scanning electron microscopy (SEM) and transmission electron microscopy (TEM).

\section{Experimental}

As-produced HiPco SWNTs were purchased from Carbon Nanotechnology, Inc. Material was preliminary dispersed in isopropanol at $300 \mathrm{~K}$ for $5-7 \mathrm{~h}$ in an ultrasonic bath and was then deposited on a $1 \times 1 \mathrm{~cm} \mathrm{Si}(100)$ substrate. After drying at room temperature, the samples were placed within a quartz cell $[26,27]$ connected to a UHV glass system [28]. Both the heating of the SWNTs and their interaction with deuterium has been performed in situ in two steps. In the first step all samples were heated at $670 \mathrm{~K}$ in a vacuum $\left(10^{-5} \mathrm{~Pa}\right)$ for $8 \mathrm{~h}$, then at $670 \mathrm{~K}$ in $133 \mathrm{~Pa}$ deuterium for $2 \mathrm{~h}$, and finally they were heated again in vacuum at $1000 \mathrm{~K}$ for $1 \mathrm{~h}$ after the system was evacuated to a pressure below $10^{-6} \mathrm{~Pa}$. In the second step the quartz cell was maintained in a cooling bath at $78 \mathrm{~K}$ or $273 \mathrm{~K}$ and the SWNT samples were exposed to a mixture of molecular $\left(\mathrm{D}_{2}\right)$ and atomic $(\mathrm{D})$ deuterium gas, produced by the thermal dissociation of $\mathrm{D}_{2}$ on a hot tungsten filament $\left(10 \mathrm{~cm}\right.$ long and $2.7 \times 10^{-2} \mathrm{~cm}$ in diameter), suspended in a quartz cell at a distance of $2.5 \mathrm{~cm}$ from the samples. The temperatures of the resistively heated tungsten filament $\left(T_{\mathrm{W}}\right)$ was $1020 \mathrm{~K}$ and $1550 \mathrm{~K}$, as measured during dissociation of deuterium at pressures of 0.6 and $60 \mathrm{~Pa}$, respectively, using an optical pyrometer (Mikron M190, USA). Deuterium was purified by diffusion through a hot palladium thimble.

Morphological and chemical examination of the SWNT material before and after thermal and atomic deuterium treatment was performed ex situ in separate analytical systems. SEM observation (LEO 1550 FEG SEM) was carried out to study the SWNT surface morphology. TEM studies (Philips CM30 Twin (S)TEM), on the other hand, were used to obtain information regarding the structure of separate bundles of carbon nanotubes. XPS analysis (PHI Quantera scanning $\mathrm{X}$-ray microprobe) in the low-photoelectron binding energy range allowed the electronic structure of the SWNTs, as well as the nature of carbon specimens formed after interaction with thermally atomised deuterium, to be identified.

The TEM specimens of selected samples of SWNTs were prepared in cross-section using the recipe described in Ref. [29], but instead of M-bond 610 the Gatan G1 two-component epoxy resin was used. Also, SWNT material scraped from the original samples was analysed by TEM. For this purpose the samples were prepared by adding isopropanol and dispersing the suspended tubes in an ultrasonic bath for several minutes. A drop of the suspension was then placed onto a holey carbon film coated copper grid and air dried for TEM observation. 


\section{Results}

\subsection{Determination of the deuterium atomisation efficiency} by $T D M S$

Thermal dissociation of deuterium at $0.6 \mathrm{~Pa}$ on a hot tungsten filament is a clean, low yield source of atomic $\mathrm{D}$, for which the efficiency is well defined [27,30,31]. The equilibrium atomic deuterium pressure generated under our experimental conditions $\left(T_{\mathrm{W}}=1020 \mathrm{~K}\right.$, $\left.P\left(\mathrm{D}_{2}\right)=0.6 \mathrm{~Pa}\right)$ was $\approx 10^{-7} \mathrm{~Pa}[27]$.

$\mathrm{D}_{2}$ atomisation at $60 \mathrm{~Pa}$ is however, accompanied by gas phase recombination of the deuterium atoms because the mean free path of deuterium atoms produced on the hot $\mathrm{W}$ filament is much shorter $(<0.1 \mathrm{~cm})$ than the distance between the $\mathrm{W}$ filament and the SWNT sample. Such a source, i.e., a gas mixture of $\left(\mathrm{D}+\mathrm{D}_{2}\right)$, for atomic deuterium adsorption experiments is rather ill-defined. Nevertheless, it is possible to evaluate its efficiency in creating atomic D experimentally using an annealed gold film as a selective detector of atomic deuterium in the temperature range $78-300 \mathrm{~K}$ [27].

In separate experiments, the thin Au layers $(40 \mathrm{~nm}$ thick) were evaporated on the inner wall of the quartz cell at $78 \mathrm{~K}$ and exposed in situ to the $\left(\mathrm{D}+\mathrm{D}_{2}\right)$ gas mixture at pressures $P\left(\mathrm{D}_{2}\right)$ of 0.6 and $60 \mathrm{~Pa}$, at $T_{\mathrm{W}}$ of $1020 \mathrm{~K}$ and $1550 \mathrm{~K}$, respectively. The deuterium adsorbate coverage was subsequently determined using the thermal desorption mass spectroscopy (TDMS) method $[26,27]$. A mass spectrometer was applied as the selective detector of the deuterium pressure in the gas phase. The TDMS spectra, taken after the same exposure time as was used for the SWNT samples, are presented in Fig. 1.

TDMS peaks appearing below $200 \mathrm{~K}$ in both thermal desorption spectra, are assigned to surface states of an adatomic deuterium adsorbate whereas the TDMS peak within a temperature range $200-290 \mathrm{~K}$ is associated with the penetration of D species within the Au film [27]. A direct comparison of the amount of deuterium desorbed within both TDMS peaks shows that the relative efficiency of the reactive $\left(D+D_{2}\right)$ gas mixture production at $1550 \mathrm{~K}$ and $60 \mathrm{~Pa}$ is about 4 times higher than the corresponding one at $1020 \mathrm{~K}$ and $0.6 \mathrm{~Pa}$. The deuterium gas mixture produced under the former condition impacts the Au film with higher thermal energy, leading to a significant incorporation of deuterium atoms within the Au film at $78 \mathrm{~K}$ (see high-temperature TDMS peak of spectrum 2 in Fig. 1).

\subsection{SEM analysis}

Fig. 2a shows the SEM image of a SWNT sample after interaction with molecular deuterium at $P\left(\mathrm{D}_{2}\right)=133 \mathrm{~Pa}$ and $670 \mathrm{~K}$ for $2 \mathrm{~h}$. This procedure was applied to all investigated SWNT samples, prior to the

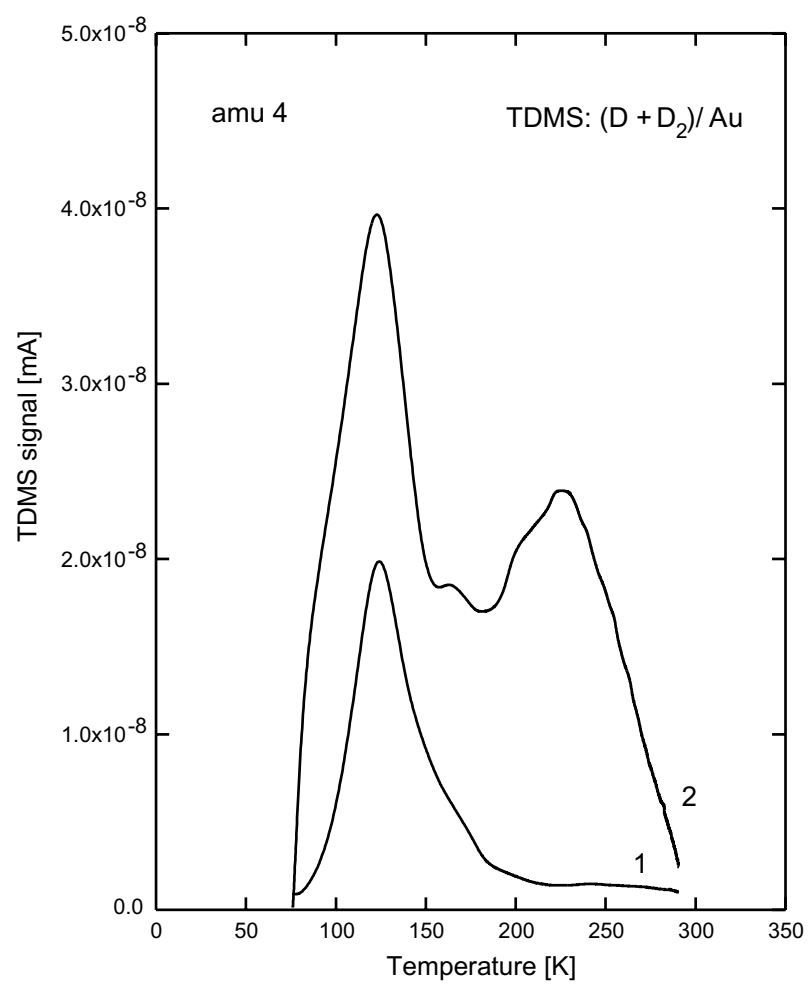

Fig. 1. TDMS spectra of deuterium from thin Au films. The adsorption temperature was $78 \mathrm{~K}$. Spectrum (1) was obtained after $60 \mathrm{~min}$ exposure to atomic $\mathrm{D}$ generated on a hot $\mathrm{W}$ filament $\left(T_{\mathrm{W}}=1020 \mathrm{~K}\right)$ at a $\mathrm{D}_{2}$ pressure, $P\left(\mathrm{D}_{2}\right)$, of $0.6 \mathrm{~Pa}$. Spectrum (2) was obtained after 60 min exposure to a $\left(\mathrm{D}+\mathrm{D}_{2}\right)$ gas mixture produced on a hot W filament $\left(T_{\mathrm{W}}=1550 \mathrm{~K}\right)$ at a $\mathrm{D}_{2}$ pressure, $P\left(\mathrm{D}_{2}\right)$, of $60 \mathrm{~Pa}$.

atomised deuterium treatment. Fig. $2 \mathrm{~b}$ shows the SEM image of the SWNTs after $1 \mathrm{~h}$ exposure at $273 \mathrm{~K}$ to the $\left(\mathrm{D}+\mathrm{D}_{2}\right)$ gas mixture produced at $T_{\mathrm{W}}=1020 \mathrm{~K}$ and $P\left(\mathrm{D}_{2}\right)=0.6 \mathrm{~Pa}$. Fig. $2 \mathrm{c}$ and $\mathrm{d}$, on the other hand, show the SEM images of the SWNT samples after $1 \mathrm{~h}$ exposure at 78 and $273 \mathrm{~K}$, respectively, to the $\left(\mathrm{D}+\mathrm{D}_{2}\right)$ gas mixture produced on the hot tungsten filament at $T_{\mathrm{W}}=1550 \mathrm{~K}$ and a pressure $P\left(\mathrm{D}_{2}\right)$ of $60 \mathrm{~Pa}$.

Prolonged interaction with atomic deuterium produced at $T_{\mathrm{W}}=1020 \mathrm{~K}$ leads to visible transformation of the SWNTs. Large carbon ropes $(50-80 \mathrm{~nm}$ in diameter) appear (see deeper planes of the SEM image in Fig. 2b) in addition to disordered bundles of SWNTs, which were also observed in the original material before the atomised deuterium treatment (Fig. 2a). Distinct changes in the SEM image were observed after exposing the SWNTs to the $\left(\mathrm{D}+\mathrm{D}_{2}\right)$ gas mixture produced at $T_{\mathrm{W}}=1550 \mathrm{~K}$ (Fig. 2c and d); it can be seen that the bundles of SWNTs have become shorter, forming a kind of "coral reef" structure.

Partial $\left(D+D_{2}\right)$ interaction induced degradation of the SWNT material was observed when it remained in a cooling bath at $78 \mathrm{~K}$ (Fig. 2c), and extended degradation when kept at $273 \mathrm{~K}$ (Fig. 2d). 

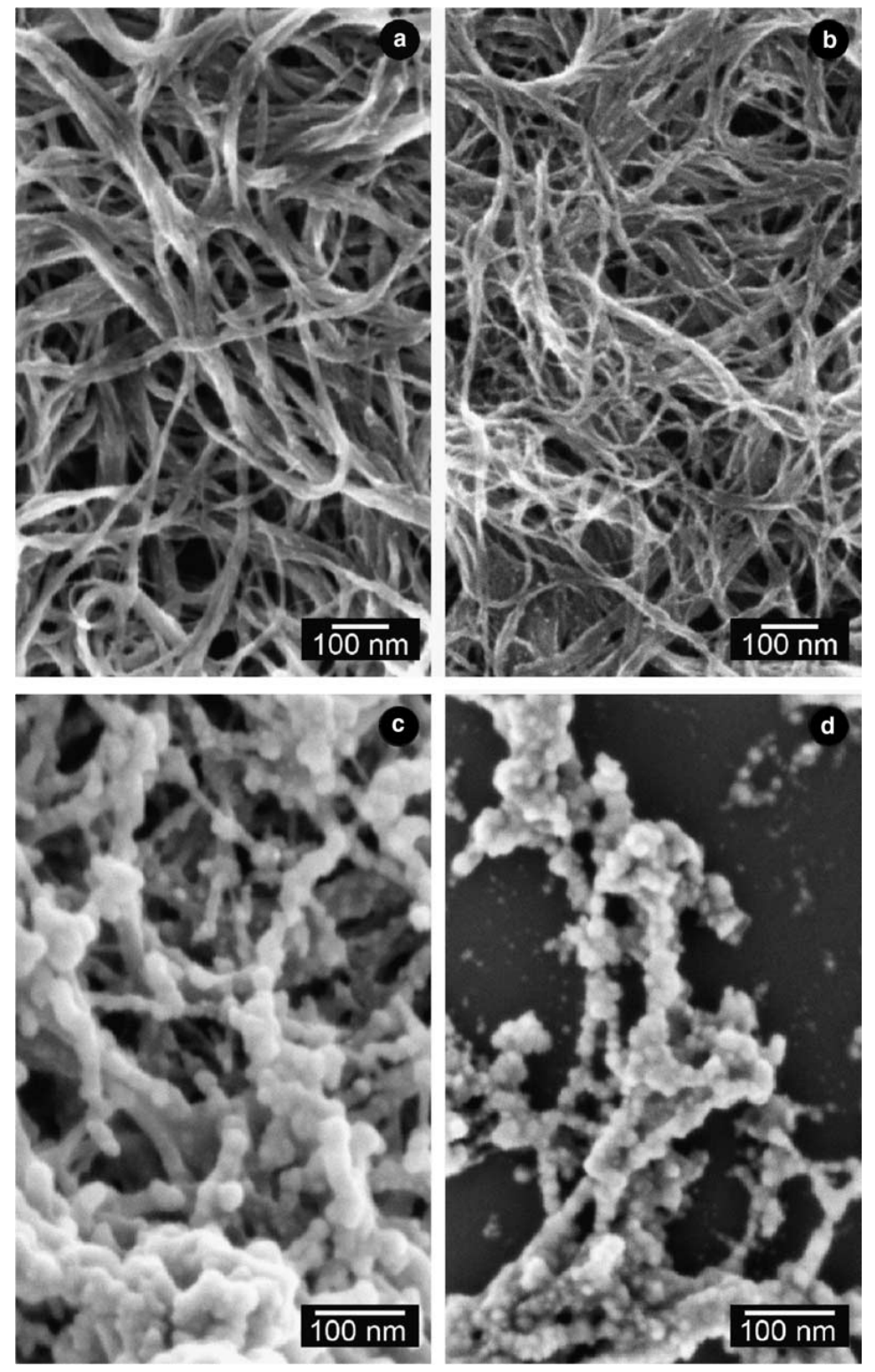

Fig. 2. SEM images of SWNTs: (a) after heating in vacuum $\left(10^{-5} \mathrm{~Pa}\right)$ at $670 \mathrm{~K}$ for $8 \mathrm{~h}$, then heating in $\mathrm{D}_{2}(133 \mathrm{~Pa})$ at $670 \mathrm{~K}$ for $2 \mathrm{~h}$ and finally heating in vacuum $\left(10^{-5} \mathrm{~Pa}\right)$ at $1000 \mathrm{~K}$ for $1 \mathrm{~h}$, (b) after the procedure in (a) followed by exposing the SWNTs for 60 min to atomic deuterium produced on a hot $\mathrm{W}$ filament $\left(T_{\mathrm{W}}=1020 \mathrm{~K}\right)$ at $P\left(\mathrm{D}_{2}\right)=0.6 \mathrm{~Pa}$. The temperature of the SWNT sample was kept at $273 \mathrm{~K}$, (c) after the procedure in (a) followed by a $\left(\mathrm{D}+\mathrm{D}_{2}\right)$ gas mixture treatment at $78 \mathrm{~K}$ for 60 min. The $\left(\mathrm{D}+\mathrm{D}_{2}\right)$ gas mixture was produced on a hot $\mathrm{W}$ filament $\left(T_{\mathrm{W}}=1550 \mathrm{~K}\right)$ at $P\left(\mathrm{D}_{2}\right)=60 \mathrm{~Pa}$, (d) after the procedure in (a) followed by a $\left(\mathrm{D}+\mathrm{D}_{2}\right)$ gas mixture treatment at $273 \mathrm{~K}$ for $60 \mathrm{~min}$. The source of deuterium was the same as in (c).

\subsection{TEM analysis}

TEM examination has been realised in two ways. The SWNT material, scraped from the samples, was analysed after each deuterium treatment procedure. However, a selected SWNT sample was investigated in cross-section in order to evaluate the real thickness of the SWNT layer and to reveal the distribution of the SWNT material as exposed to the $\left(\mathrm{D}+\mathrm{D}_{2}\right)$ gas mixture without the scraping induced deformation of the SWNT layer.

\subsubsection{Cross-sectional TEM analysis}

The SWNT sample after $1 \mathrm{~h}$ interaction with the $\left(\mathrm{D}+\mathrm{D}_{2}\right)$ gas mixture produced at $T_{\mathrm{W}}=1020 \mathrm{~K}$ and $P\left(\mathrm{D}_{2}\right)=0.6 \mathrm{~Pa}$ has been analysed in cross-section. Fig. 3 a shows the result of this analysis. Randomly distributed bundles of SWNTs form a carbon nanotube layer of thickness between $200 \mathrm{~nm}$ and $600 \mathrm{~nm}$. These bundles, however, are not homogeneous in diameter. The diameter, as measured directly from the cross-sectional TEM images (Fig. 3), was in the range of $20-80 \mathrm{~nm}$, in 

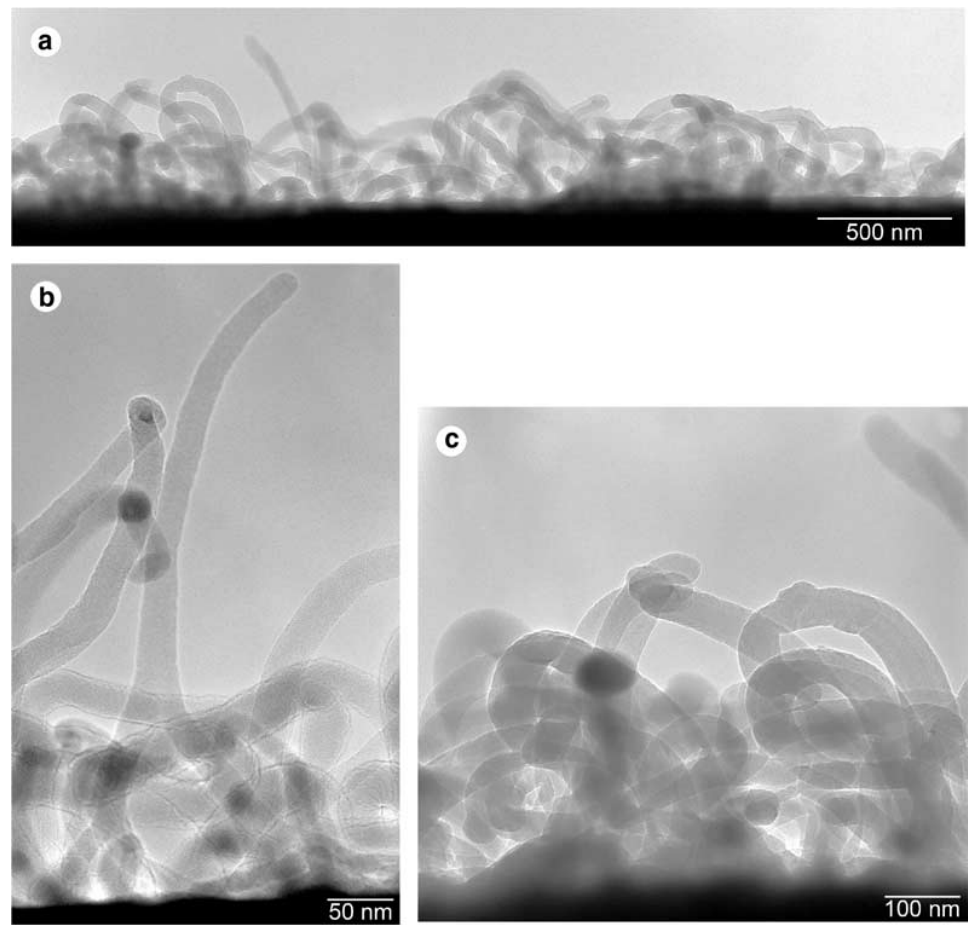

Fig. 3. Cross-sectional TEM images of the SWNT sample after its exposure to atomic deuterium produced on a hot W filament at $T_{\mathrm{W}}=1020 \mathrm{~K}$ and $P\left(D_{2}\right)=0.6 \mathrm{~Pa}$ for $60 \mathrm{~min}$. The temperature of the SWNT sample was kept at $273 \mathrm{~K}$. Image (a) illustrates the large cross-sectional area whereas images (b) and (c) show the magnification of selected parts of image (a).

good agreement with the corresponding values observed by SEM (Fig. 2b).

\subsubsection{TEM analysis of the scraped SWNT material}

Fig. 4 shows TEM images of the SWNT material scraped from the SWNT sample after prolonged interaction with the $\left(\mathrm{D}+\mathrm{D}_{2}\right)$ gas mixture produced at $T_{\mathrm{W}}=1020 \mathrm{~K}$. The high-magnification TEM image of selected SWNT bundles (Fig. 4a) shows the surface of SWNT bundles to be torn and coated with amorphous carbon material. In addition to the SWNT bundles exhibiting a diameter between 20 and $25 \mathrm{~nm}$, thicker ropes (40-80 $\mathrm{nm}$ in diameter) have also been detected (Fig. 4b). Single nanotubes were not observed in the scraped SWNT material. An analysis of the cross-section shape of the selected ropes (marked 1 and 2 in Fig. 4b) is presented in the discussion.

The material scraped from the SWNT sample, which was exposed to the $\left(\mathrm{D}+\mathrm{D}_{2}\right)$ gas mixture produced at $T_{\mathrm{W}}=1550 \mathrm{~K}$, exhibits a differential structural morphology depending on the temperature of the SWNTs (Figs. 5 and 6). In the TEM image (a) of Fig. 5, recorded for the SWNT material kept at $78 \mathrm{~K}$ during the $\left(\mathrm{D}+\mathrm{D}_{2}\right)$ interaction, we found evidence for single nanotubes (1.1-1.3 nm in diameter) and SWNTs assembled into bundles consisting of 2-10 nanotubes of the same diameter. Only a few SWNT bundles, similar to those observed in the pristine material, were observed. SWNTs with diameters double those of single-wall nanotubes $(2.2-2.6 \mathrm{~nm})$ were found to be associated with the bundle of SWNTs as shown in Fig. 5b.

Significant transformation of the SWNT material, kept at $273 \mathrm{~K}$ during the $\left(\mathrm{D}+\mathrm{D}_{2}\right)$ interaction, is revealed in the TEM images of Fig. 6. Neither the single nanotubes nor the bundles formed by long SWNTs are observed. Instead a "coral reef"-like structure is observed (Fig. 6a). This structure is formed by nanoparticles and nanocapsules, $10-40 \mathrm{~nm}$ in length, isolated by a thin carbon skin, $2.5 \mathrm{~nm}$ thick (see Fig. 6b). The TEM images, which display the "coral reef"-like structure, were also found occasionally in the SWNT material kept at $78 \mathrm{~K}$ during the $\left(\mathrm{D}+\mathrm{D}_{2}\right)$ interaction, in correspondence with the SEM observations depicted in Fig. 2c and $\mathrm{d}$.

\subsection{XPS analysis}

XPS element analysis was used to determine the surface concentration of Fe impurities in the SWNT material and valence-band photoelectron spectra were investigated to characterise the electronic states of SWNTs as a result of their interaction with deuterium, using X-ray excitation (monochromatic AlK $\alpha$ X-ray source, $1486.6 \mathrm{eV}$ ). All spectra were acquired with a $0.1 \mathrm{eV} / \mathrm{step}$ energy interval and were calibrated relative to the reference C 1s XPS peak at $284.8 \mathrm{eV}$. 

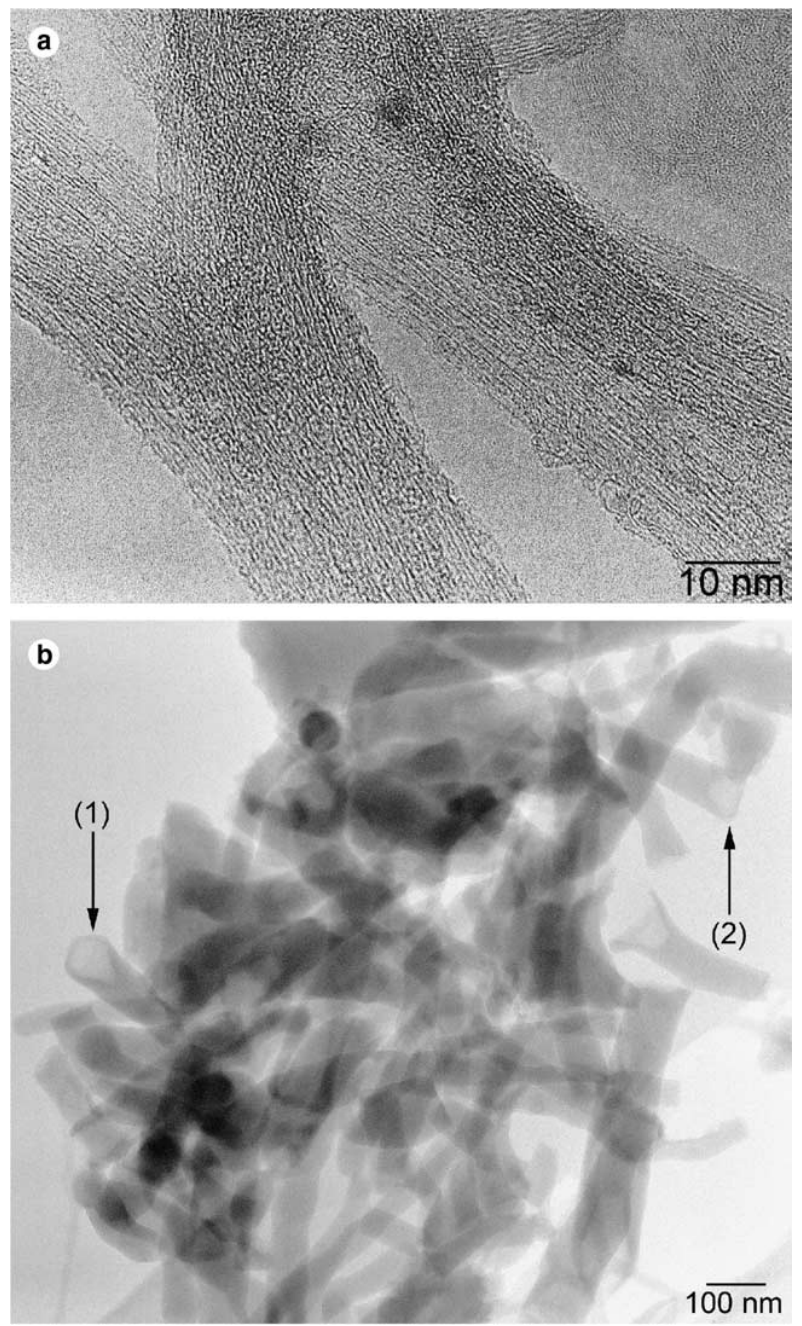

Fig. 4. TEM images of the SWNT material scraped from the samples presented in Fig. 3. High-magnification TEM image (a) shows the SWNT bundle, and the low-magnification TEM image (b) presents thick ropes of bundles characterised by square- (1) and triangularcross-sections (2).

The surface of the deuterium treated SWNT samples as well as the surface of the corresponding samples after 3 min of $\mathrm{Ar}^{+}$sputtering were analysed. The argon ion gun was operated at $1 \mathrm{kV}$ and a sputter rate of $1.5 \mathrm{~nm} / \mathrm{min}$.

Table 1 shows the results of the analysis of the Fe surface concentration in various SWNT samples after deuterium treatment as described in Section 2. It can be seen that the surface concentration of $\mathrm{Fe}$ in pristine SWNT material differs from the bulk concentration ${ }^{\mathrm{a}}$ as determined by Carbon Nanotechnology Inc., the reason being that Fe nanoparticles, included within SWNTs, are screened by carbon material. A significant increase in Fe surface concentration is however, observed after intensive $\left(D+D_{2}\right)$ treatment resulting in a massive reconstruction of bundles of SWNTs into a "coral reef"-like structure and partial degradation of SWNT material (see Figs. 2c, d, and 6).
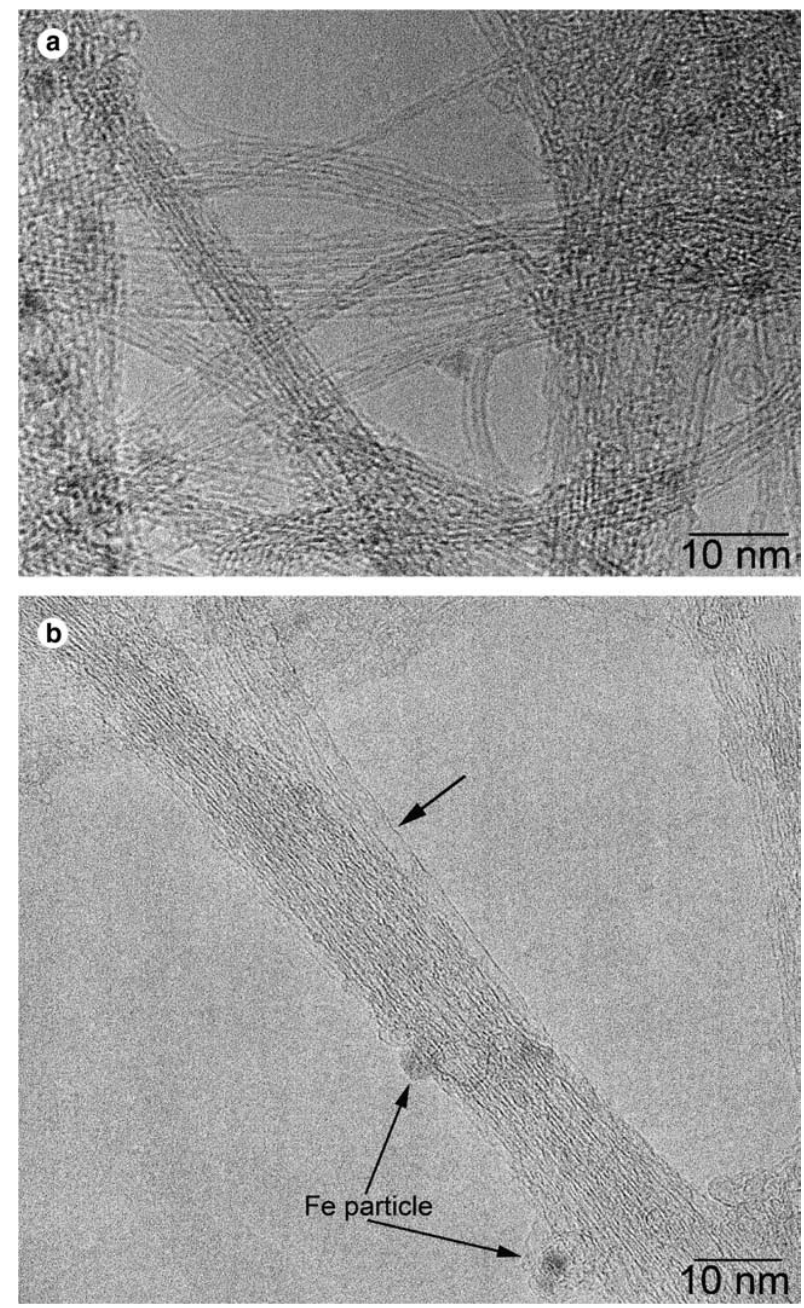

Fig. 5. High-magnification TEM images of the SWNT material scraped from the sample after its exposure at $78 \mathrm{~K}$ to the $\left(\mathrm{D}+\mathrm{D}_{2}\right)$ gas mixture produced on a hot $\mathrm{W}$ filament $\left(T_{\mathrm{W}}=1550 \mathrm{~K}\right)$ at $P\left(\mathrm{D}_{2}\right)=60 \mathrm{~Pa}$. Image (a) shows a bundle of single nanotubes. Image (b) reveals the coalescence of the outer bundle of nanotubes (marked by the arrow). A small Fe nanoparticle, included within the SWNT bundle is also shown in (b).

Fig. 7a shows the XPS valence-band spectra of the SWNT sample, which was exposed to a low deuterium atomic gas phase density $\left(T_{\mathrm{W}}=1020 \mathrm{~K}, P\left(\mathrm{D}_{2}\right)=0.6 \mathrm{~Pa}\right.$, $P(\mathrm{D}) \cong 10^{-7} \mathrm{~Pa}$ ), before (line 1), and after (line 2) argon ion sputtering. Fig. 7b on the other hand, shows the corresponding spectra obtained after interaction with the $\left(\mathrm{D}+\mathrm{D}_{2}\right)$ gas mixture generated at $T_{\mathrm{W}}=1550 \mathrm{~K}$ and $P\left(\mathrm{D}_{2}\right)=60 \mathrm{~Pa}$.

Three broad peak areas, characterised by weakly distinguished features, can be seen in the XPS valence-band spectrum in the binding energy (BE) range of 2-10, 1619 and $\approx 26 \mathrm{eV}$, respectively (Fig. 7a, line 1). This spectrum can be interpreted as a superposition of features from SWNT [32,33] and graphite-like species [34]. Graphite-like species are removed from the SWNT sam- 

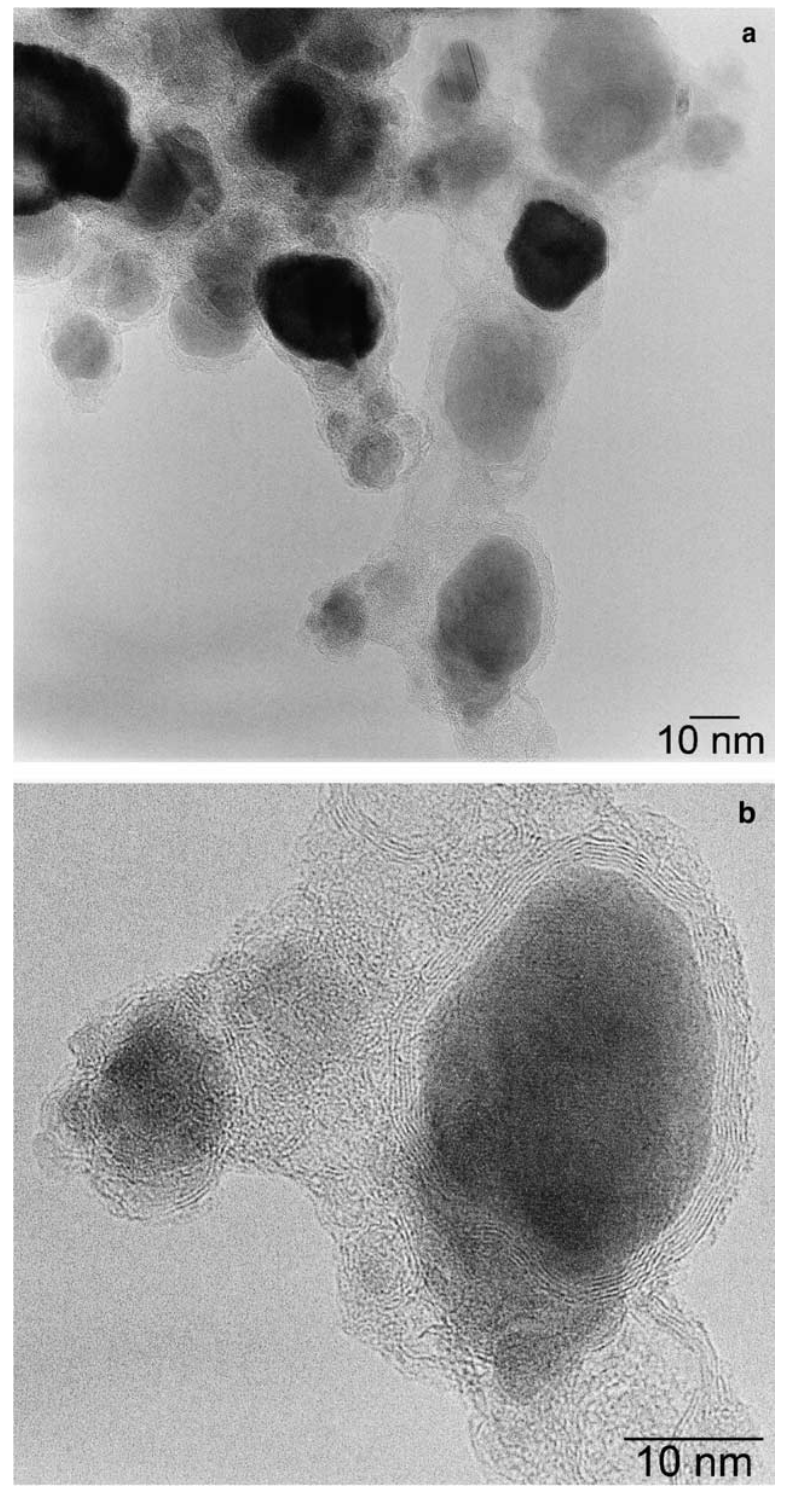

Fig. 6. (a) TEM image of the SWNT material scraped from the sample after exposing it to the $\left(\mathrm{D}+\mathrm{D}_{2}\right)$ gas mixture at $273 \mathrm{~K}$ for $60 \mathrm{~min}$. The $\left(\mathrm{D}+\mathrm{D}_{2}\right)$ gas mixture was produced on a hot $\mathrm{W}$ filament $\left(T_{\mathrm{W}}=1550 \mathrm{~K}\right)$ at $P\left(\mathrm{D}_{2}\right)=60 \mathrm{~Pa}$, (b) zoomed-in view of a selected area in (a).

ple during $\mathrm{Ar}^{+}$sputtering, making the peaks at 9 and $18 \mathrm{eV} \mathrm{BE}$, characteristic for SWNTs [32,33], more distinct (see Fig. 7a, line 2).

The XPS valence-band spectra of the SWNT material after intensive $\left(D+D_{2}\right)$ treatment exhibit more distinct features (Fig. 7b). The peaks at 5.1 and $24 \mathrm{eV} \mathrm{BE}$ were found to be associated with graphite-like species [34] while the latter peak is associated with MWNTs [35]. Argon ion sputtering of this material causes the low BE XPS peak to decrease whereas the higher energy XPS peak is split into two states at $\sim 21$ and $\sim 24 \mathrm{eV}$ BE.
Table 1

Surface concentration of $\mathrm{Fe}$ in SWNT material after deuterium treatment at various experimental conditions, as determined by XPS

\begin{tabular}{ll}
\hline SWNT material & $\begin{array}{l}\text { Relative atomic Fe } \\
\text { surface concentration }(\%)\end{array}$ \\
\hline Original pristine material & $0.4\left(3.1^{\mathrm{a}}\right)$ \\
After atomic deuterium treatment & 0.6 \\
$\quad\left(T_{\mathrm{W}}=1020 \mathrm{~K}, P\left(\mathrm{D}_{2}\right)=0.6 \mathrm{~Pa}\right)$ & \\
$\quad$ for 60 min at $273 \mathrm{~K}$ & \\
After $\left(\mathrm{D}+\mathrm{D}_{2}\right)$ gas mixture treatment & 9.4 \\
$\quad\left(T_{\mathrm{W}}=1550 \mathrm{~K}, P\left(\mathrm{D}_{2}\right)=60 \mathrm{~Pa}\right)$ & \\
$\quad$ for $60 \mathrm{~min}$ at $273 \mathrm{~K}$ & \\
\hline
\end{tabular}

${ }^{\text {a }}$ Bulk concentration-originated from the Certificate of Analysis performed at Carbon Nanotechnology Inc.
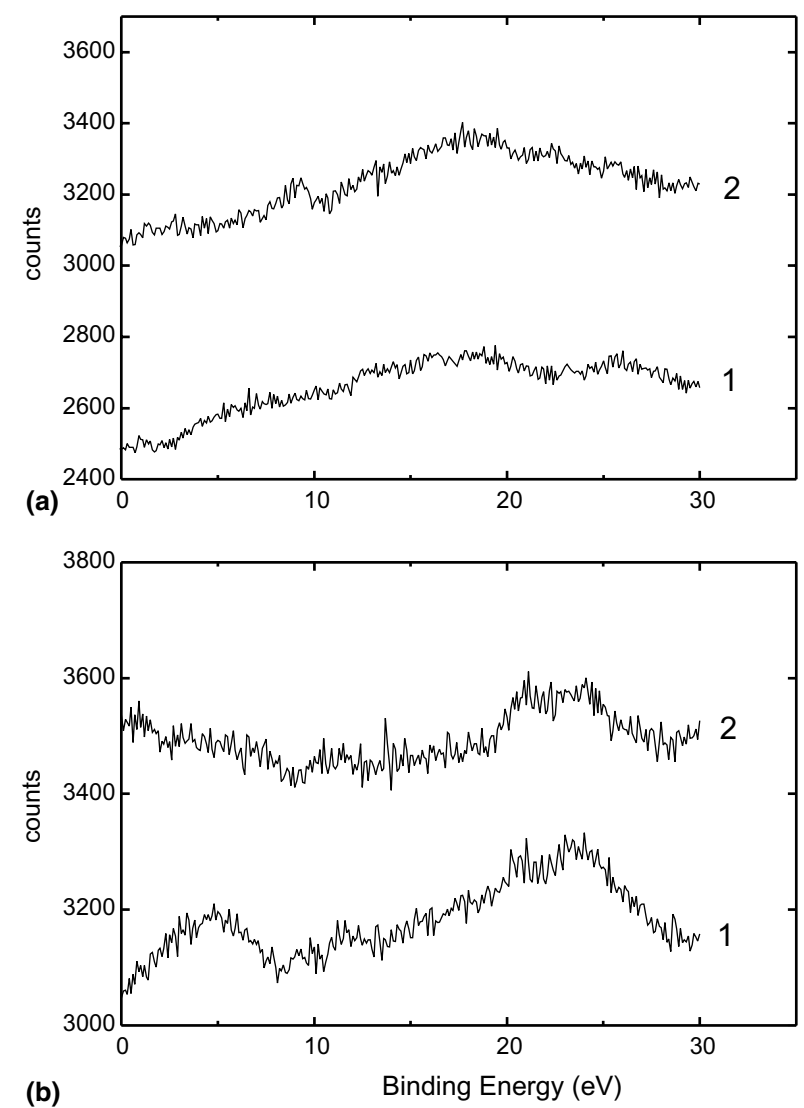

Fig. 7. The XPS valence-band spectra of the SWNT samples, which were exposed for $60 \mathrm{~min}$ to the $\left(\mathrm{D}+\mathrm{D}_{2}\right)$ gas mixture generated on a hot $\mathrm{W}$ filament at: (a) $T_{\mathrm{W}}=1020 \mathrm{~K}, P\left(\mathrm{D}_{2}\right)=0.6 \mathrm{~Pa}$ and (b) $T_{\mathrm{W}}=1550 \mathrm{~K}, P\left(\mathrm{D}_{2}\right)=60 \mathrm{~Pa}$. Lines 1 show the spectra of the "as received" SWNT samples whereas lines 2 represent the spectra after $3 \mathrm{~min}$ of mild Argon ion sputtering (sputter rate was $1.5 \mathrm{~nm} / \mathrm{min}$ ).

\section{Discussion}

It is important in this discussion to distinguish two different experimental conditions in which the SWNTdeuterium interaction was carried out. In the first, a low density atomic deuterium gas phase, generated at $P\left(\mathrm{D}_{2}\right)=0.6 \mathrm{~Pa}$ and $T_{\mathrm{W}}=1020 \mathrm{~K}$, was impacted on the 
SWNT samples which were kept at $273 \mathrm{~K}$. In the second, the SWNT material, kept at 78 or $273 \mathrm{~K}$, was exposed more intensively by the $\left(\mathrm{D}+\mathrm{D}_{2}\right)$ gas mixture produced at $T_{\mathrm{W}}=1550 \mathrm{~K}$ and $P\left(\mathrm{D}_{2}\right)=60 \mathrm{~Pa}$. The deuterium particles, produced in this experimental regime, collide with the SWNT material with relatively higher thermal energy $(T \leqslant 1550 \mathrm{~K}, k T \leqslant 0.13 \mathrm{eV})$, and with an efficiency 4 times higher than detected under low $\mathrm{D}_{2}$ pressure conditions (Section 3.1). Evidently, both the deuterium atoms and thermal $\mathrm{D}_{2}$ molecules are active in the interaction process with the surface of the SWNTs and the higher deuterium particle density results in a significantly higher deuterium adsorption efficiency.

From the results presented it is obvious that prolonged interaction of the gas with low atomic deuterium concentration $\left(T_{\mathrm{W}}=1020 \mathrm{~K}\right.$ and $\left.P\left(\mathrm{D}_{2}\right)=0.6 \mathrm{~Pa}\right)$ with the SWNT bundles, affects their size and relative layout. Both SEM (Fig. 2b) and TEM (Figs. 3 and 4) images disclose the formation of SWNT ropes 40 $80 \mathrm{~nm}$ in diameter, in addition to bundles of $20-25 \mathrm{~nm}$ in diameter, which were also present in the pristine material prior to atomic deuterium treatment (Fig. 2a). Both the thickness and the cross-section shape of these ropes appeared to be inhomogeneous. Especially interesting was to identify the ropes of triangular and square cross-sections (Fig. 4b). That observation leads us to suppose that the ropes were formed as a result of a conglomeration of SWNT bundles. In order to verify our assumption we analyzed the cross-section shapes of two ropes selected in Fig. 4b. The first one, marked by 1 in Fig. 4b, shows a square-shaped cross-section, while the second, marked by 2 in Fig. 4b, shows a triangularshape. Magnifications of the selected rope areas (1 and 2) are presented in Fig. 8 together with a geometric analysis of their cross-section shape. For a model consideration we have taken the SWNT bundle diameter to be $25 \mathrm{~nm}$ as we found in Fig. 4a. Using the simple analytical formulae, modeling the cross-sections of ropes 1 and 2 (Fig. 8), for the corresponding values of the square $\left(R_{\mathrm{s}}\right)$ and triangular $\left(R_{\mathrm{t}}\right)$ cross-section diagonals we arrived at 61 and $47 \mathrm{~nm}$, respectively. These values are close to those as measured directly by TEM (see images 1 and 2 of Fig. 8), $R_{\mathrm{s}}=60 \mathrm{~nm}$ and $R_{\mathrm{t}}=48 \mathrm{~nm}$, respectively.

The conglomeration of SWNTs into thicker ropes as a result of prolonged atomic deuterium interaction can be interpreted as follows:

The deuterium atoms generated under molecular conditions impact the SWNTs with low thermal energy $(k T \leqslant 0.09 \mathrm{eV})$ but still high enough to form chemisorbed $\mathrm{C}-\mathrm{D}$ groups. The reaction barrier for chemisorption was estimated theoretically to be $1 \mathrm{eV}$ for perfect nanotubes [16] and small compared to $\mathrm{kT}$ at $300 \mathrm{~K}(0.03 \mathrm{eV})$ for highly distorted carbon nanotubes [20]. The last value seems to be more representative for the SWNT material
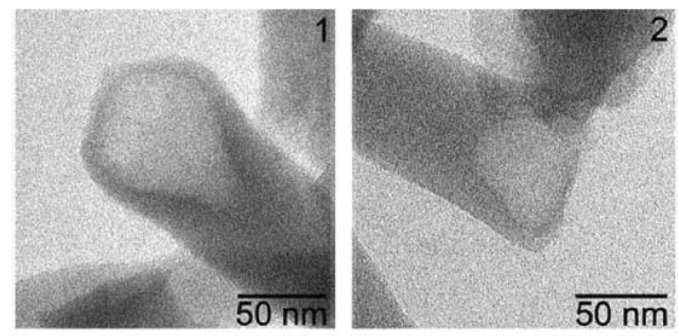

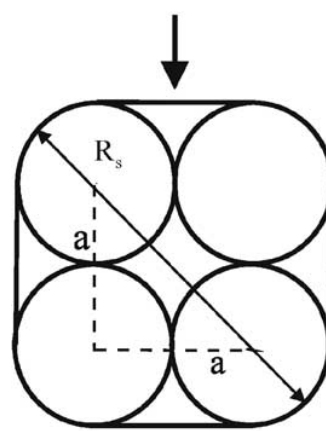

$R_{S}=a(1+\sqrt{ } 2)$

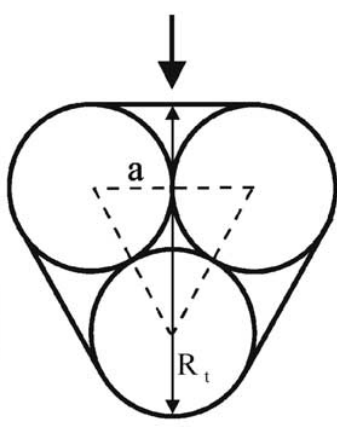

$$
R_{t}=a\left(1+\frac{\sqrt{3}}{2}\right)
$$

Fig. 8. The analysis of the cross-sectional shapes of two SWNT ropes selected in Fig. 4b. The TEM image magnifications of the square- (1) and triangular- (2) cross-section areas are shown on top. Below are presented their schematic model approximation together with, placed in the bottom, the formulas relating square- $\left(R_{\mathrm{s}}\right)$ and triangular- $\left(R_{\mathrm{t}}\right)$ cross-section diagonals of the corresponding SWNT ropes to the SWNT bundle diameter $(a)$.

presented in this paper (Fig. 2a). The SWNT material, maintained at low constant temperature $(273 \mathrm{~K})$, accommodates energy of the deuterium atoms produced on the hot W filament at $1020 \mathrm{~K}$. Due to the low energy of the D atoms this reaction is limited to the near surface region. The appearing C-D groups initiate the formation of deuterocarbon species as a result of their prolonged interaction with atomic deuterium. However, the energy of the D atoms impinging on the SWNT surface covered by the deuterium and deuterocarbon species is too low to remove all products of this interaction from the surface. These ones are aggregated on the outer walls of the SWNT bundles leading to a deformation of their surface and cause the SWNT bundles to be torn (Fig. 4a) and be coated with amorphous carbon material (see Fig. 7a in Section 3.4). The adjacent bundles path together and generate a common inter-bundle tube region formed by surfaces of tearing bundles giving rise to the thick ropes formation. This "patching and tearing" mechanism was proposed more recently by Lopez et al. [23] to understand the SWNT to MWNT transformation. Nevertheless, this mechanism also seems to be responsible for the formation of SWNT ropes via SWNT bundle conglomeration.

A dramatic change of the SWNT structure has been observed after intensive interaction with the $\left(\mathrm{D}+\mathrm{D}_{2}\right)$ gas mixture generated at $T_{\mathrm{W}}=1550 \mathrm{~K}$ and $P\left(\mathrm{D}_{2}\right)=$ $60 \mathrm{~Pa}$. The SWNT material kept at 78 and $273 \mathrm{~K}$ has 
undergone massive reconstruction into the "coral reef"like structure (Fig. 2c and d, respectively). It can be seen that part of the SWNT material, kept at $273 \mathrm{~K}$, is lost (Fig. 2d) due to its interaction with deuterium, probably via volatile deuterocarbon species desorption [36,37]. The SWNT degradation process is moderated at $78 \mathrm{~K}$ allowing the SWNT structures, being the intermediate products of this interaction, to be observed. Within the SWNT material kept at $78 \mathrm{~K}$ we found terminated single carbon tubes (Fig. 5a) and bundles in which the outer tubes have been affected by significant erosion as well, as diameter doubling coalescence (Fig. 5b). It is worth noting that SWNT coalescence has been observed previously after the SWNT annealing under Ar flow, but at a temperature higher than $1800 \mathrm{~K}[21,22]$. In our experimental conditions the process is initiated at a much lower temperature probably by deuterium induced chemical erosion [36,37] of the neighbouring tubes of the bundle. Such a deformation of the SWNTs gives rise to their coalescence according to the "patching and tearing" mechanism [23].

Particularly interesting seems to be the formation of the "coral reef"-like carbon nanostructures as a result of prolonged thermal $\left(\mathrm{D}+\mathrm{D}_{2}\right)$ gas mixture treatment (Fig. 2c and d). TEM images disclose more details of this structure (Fig. 6). One can distinguish nanocapsules and nanoparticles isolated by a thin carbon skin. The formation of similar carbon structures has been reported previously as a result of various experimental procedures [38,39]. Yasuda et al. [38] applied electrochemical preparation of polyyne-containing carbons followed by an electron beam irradiation treatment at $873 \mathrm{~K}$ and low pressure. On the other hand, Teunissen et al. [39] used methane high-temperature encapsulation of the bimetallic particles on alumina. However, in both cases small particles of metals [38,39], oxides [39] or carbides [40] worked as a core to form the nanoparticles and nanocapsules. Our original SWNT material consists of $\approx 3.1 \%$ Fe. XPS results showed that after interaction with the thermal $\left(D+D_{2}\right)$ gas mixture, part of the carbon material is lost causing the relative $\mathrm{Fe}$ content to be higher than $9 \%$ (Table 1). Such a high Fe concentration suggests that the Fe particle encapsulation pathway can contribute to the transformation of the SWNT structure leading to the formation of the "coral-reef" structure. On the other hand, the Fe particle size included within the SWNTs is smaller than $5 \mathrm{~nm}$ in diameter (Fig. 5b), whereas the size of nanoencapsulated areas was measured to be $10-30 \mathrm{~nm}$ (Fig. 6). That is an indication that the encapsulation of Fe nanoparticles is only one of the mechanisms responsible for the destructive transformation of carbon nanotubes. We should also take into consideration the encapsulation of deuterium and deuterocarbon species, being the products of the SWNT-deuterium interaction. Ma et al. [17] considered $\mathrm{D}$ encapsulation in the carbon nanotubes to be possible, but at an incident energy higher than $15 \mathrm{eV}$. Deuterium atoms trapped on the inner side of the carbon wall form a metastable state characterised by a binding energy of $0.172 \mathrm{eV}$. However, deuterium atoms trapped below the surface $[41,42]$ or on the surface precovered with $\mathrm{C}-\mathrm{D}$ species can adsorb with much lower energy. The latter process results in a $\left(D+D_{2}\right)$ impact induced reaction with $\mathrm{C}-\mathrm{D}$ adspecies [37] and finally erosion of the carbon material [36,37]. Light deuterocarbon species appearing as a product of the direct deuterium impact, can be removed from the carbon material via an Eley-Rideal mechanism [36]. However, part of the deuterocarbon species appearing at high deuterium coverage can remain on the surface further initiating the massive reconstruction of the SWNTs.

It is reasonable to assume that such a massive reconstruction of SWNTs is accompanied by significant changes in the electronic structure [18]. Our XPS spectra recorded in the valence-band energy range (Fig. 7b) provide evidence for these changes. The SWNT material is transformed into a "coral reef"-like carbon nanostructure exhibiting valence-band electronic structure features similar to those observed on hydrogen-plasma modified MWNTs films [35]. The presence of deuterocarbon species within this material can be derived from a split of the XPS peak at $\sim 24 \mathrm{eV}$ (Fig. 7b). We believe that the XPS peak appearing at $\sim 21 \mathrm{eV}$ can be attributed to deuterocarbon material confined within this structure. This peak becomes more distinct after the surface region $(\sim 4.5 \mathrm{~nm}$ in depth) of the transformed SWNT material was removed by argon ion sputtering (compare lines 1and 2 in Fig. 7b), thus providing strong evidence that this peak can be attributed to deeper layers within the transformed SWNT structure. The deuterocarbon-like nature of the species associated with this peak is supported by the XPS results of Cavell et al. [43] who reported the binding energy of methane from their XPS spectra in the valence regime to be $23 \mathrm{eV}$. This value is in good agreement with the peak observed within the split XPS valence-band energy range (see line 2 in Fig. 7b). A similar splitting of peaks in the XPS valenceband spectrum was observed by $\mathrm{Yu}$ et al. [35] for MWNT films after hydrogen plasma treatment.

\section{Conclusions}

Prolonged interaction of SWNTs with atomic deuterium from the $\left(D+D_{2}\right)$ gas mixture, produced on a hot W filament at $T_{\mathrm{W}}=1020 \mathrm{~K}$ and $P\left(\mathrm{D}_{2}\right)=0.6 \mathrm{~Pa}$, leads to a conglomeration of SWNT bundles into large diameter rope type nanotubes covered by nano-aggregates of graphite material. The SWNT material undergoes a transformation into a "coral reef"-like carbon nanostructure after prolonged exposure of the SWNTs to the $\left(\mathrm{D}+\mathrm{D}_{2}\right)$ gas mixture produced at $T_{\mathrm{W}}=1550 \mathrm{~K}$ 
and $P\left(\mathrm{D}_{2}\right)=60 \mathrm{~Pa}$. This structure is formed by encapsulated $\mathrm{Fe}$ nanoparticles and deuterocarbon-like species which appear as a result of deuterium interaction with SWNT bundles and is accompanied by partial erosion of the SWNT material. The electronic structure of the SWNTs, transformed due to intensive deuterium interaction, exhibits features characteristic for hydrogenplasma modified MWNTs.

\section{References}

[1] Orimo S, Züttel A, Schlapbach L, Majer G, Fukunaga T, Fujii H. Hydrogen interaction with carbon nanostructures: current situation and future prospects. J Alloys Comp 2003;356-357:716-9.

[2] Dillon AC, Jones KM, Bekkedahl TA, Kiang CH, Bethune DS, Heben MJ. Storage of hydrogen in single-walled carbon nanotubes. Nature 1997;386:377-9.

[3] Ye Y, Ahn CC, Witham C, Fultz B, Liu J, Rinzler AG, et al. Hydrogen adsorption and cohesive energy of single-walled carbon nanotubes. Appl Phys Lett 1999;74(16):2307-9.

[4] Gülseren O, Yildirim T, Ciraci S. Tunable adsorption on carbon nanotubes. Phys Rev Lett 2001;87(11):1168021-24.

[5] Gülseren O, Yildirim T, Ciraci S. Effects of hydrogen adsorption on single-wall carbon nanotubes: metallic hydrogen decoration. Phys Rev B 2002;66:1214011-14.

[6] Arellano JS, Molina LM, Rubio A, López MJ, Alonso JA. Interaction of molecular and atomic hydrogen with $(5,5)$ and $(6,6)$ single-wall carbon nanotubes. J Chem Phys 2002;117(5):2281-8.

[7] Hou PX, Xu ST, Ying Z, Yang QH, Liu C, Cheng HM. Hydrogen adsorption/desorption behavior of multi-walled carbon nanotubes with different diameters. Carbon 2003;41(13):2471-6.

[8] Johansson E, Hjörvarsson B, Ekström T, Jacob M. Hydrogen in carbon nanostructures. J Alloys Comp 2002;330-332:670-5.

[9] Volpe M, Cleri F. Role of surface chemistry in hydrogen adsorption in single-wall carbon nanotubes. Chem Phys Lett 2003;371(3-4):476-82.

[10] Lee SM, Lee YH. Hydrogen storage in single-walled carbon nanotubes. Appl Phys Lett 2000;76(20):2877-9.

[11] Lee SM, Park KS, Choi YC, Park YS, Bok JM, Bae DJ, et al. Hydrogen adsorption and storage in carbon nanotubes. Synth Metals 2000;113(3):209-16.

[12] Cheng HM, Yang QH, Liu C. Hydrogen storage in carbon nanotubes. Carbon 2001;39(10):1447-54.

[13] Hirscher M, Becher M, Haluska M, Quintel A, Skakalova V, Choi $\mathrm{YM}$, et al. Hydrogen storage in carbon nanostructures. Alloys Comp 2002;330-332:654-8.

[14] Hirscher M, Becher M, Haluska M, Zeppelin F, Chen X, DettlaffWeglikowska U, et al. Are carbon nanostructures an efficient hydrogen storage medium. Alloys Comp 2003;356-357:433-7.

[15] Tarasov BP, Maehlen JP, Lototsky MV, Muradyan VE, Yartys VA. Hydrogen sorption properties of arc generated single-wall carbon nanotubes. Alloys Comp 2003;356-357:510-4.

[16] Ma Y, Xia Y, Zhao M, Ying M, Liu X, Liu P. Collision of hydrogen atom with single-walled carbon nanotube: adsorption, insertion, and healing. J Chem Phys 2001;115(17):8152-6.

[17] Ma Y, Xia Y, Zhao M, Ying M, Liu X, Liu P. Collisions of deuterium and tritium atoms with single-wall carbon nanotube: adsorption, encapsulation, and healing. Phys Lett A 2001;288 (3-4):207-13.

[18] Barone V, Heyd J, Scuseria GE. Interaction of atomic hydrogen with single-walled carbon nanotubes: a density functional theory study. J Chem Phys 2004;120(15):7169-73.
[19] Dillon AC, Heben MJ. Hydrogen storage using carbon adsorbents: past, present and future. Appl Phys A 2001;72(2):133-42.

[20] Srivastava D, Brenner DW, Schall JD, Ausman KD, Yu MF, Ruoff RS. Predictions of enhanced chemical reactivity at regions of local conformational strain on carbon nanotubes: kinky chemistry. J Phys Chem B 1999;103(21):4330-7.

[21] Nikolaev P, Thess A, Rinzler AG, Colbert DT, Smalley RE. Diameter doubling of single-wall nanotubes. Chem Phys Lett 1997;266(5-6):422-6.

[22] Méténier K, Bonnamy S, Béguin F, Journet C, Bernier P, Lamy de La Chapelle $\mathrm{M}$, et al. Coalescence of single-walled carbon nanotubes and formation of multi-walled carbon nanotubes under high-temperature treatments. Carbon 2002;40(10):1765-73.

[23] López MJ, Rubio A, Alonso JA, Lefrant S, Méténier K, Bonnamy S. Patching and tearing single-wall carbon-nanotube ropes into multiwall carbon nanotubes. Phys Rev Lett 2002;89(25): 2555011-14.

[24] Terrones M, Terrones H, Banhart F, Charlier J-C, Ajayan PM. Coalescence of single-walled carbon nanotubes. Science 2000;288:1226-9.

[25] Yudasaka M, Ichihashi T, Kasuya D, Kataura H, Iijima S. Structure changes of single-wall carbon nanotubes and single-wall carbon nanohorns caused by heat treatment. Carbon 2003;41(6): 1273-80.

[26] Duś R, Nowicka E, Lisowski W, Wolfram Z. Atomic hydrogen adsorption on sintered thin copper films. Appl Surf Sci 1995;90(3):277-82.

[27] Stobiński L. Molecular and atomic deuterium chemisorption on thin gold films at $78 \mathrm{~K}$ : an isotope effect. Appl Surf Sci 1996;103(4):503-8.

[28] Lisowski W. Flow technique for measuring the sticking probabilities of simultaneously adsorbed gases on metal films: application to the simultaneous adsorption of deuterium and nitrogen on thin iron film at $78 \mathrm{~K}$. Vacuum 1999;54(1-4):13-8.

[29] Park JB, Cho YS, Hong SY, Choi KS, Kim D, Choi SY, et al. Cross-sectional transmission electron microscopy of carbon nanotubes-catalyst-substrate heterostructure using a novel method for specimen preparation. Thin Solid Films 2002;415 (1-2):78-82.

[30] Brennan D, Fletcher PC. The atomization of hydrogen on tungsten. Proc Roy Soc London A 1959;250:389-408.

[31] Trainor DW, Ham DO, Kaufman F. Gas phase recombination of hydrogen and deuterium atoms. J Chem Phys 1973;58(10): 4599-609.

[32] Ruffieux P, Gröning O, Bielmann M, Gröning P. Hydrogen chemisorption on $\mathrm{sp}^{2}$-bonded carbon: influence of the local curvature and local electronic effects. Appl Phys A 2004;78: 975-80.

[33] Ramm M, Ata M, Gross Th, Unger W. Plasma-polymerized $\mathrm{C}_{60}$ films. Mater Phys Mech 2001;4:8-12.

[34] McFeely FR, Kowalczyk SP, Ley L, Cavell RG, Pollak RA, Shirley DA. X-ray photoemission studies of diamond, graphite, and glassy carbon valence bands. Phys Rev 1974;9(12):5268-78.

[35] Yu K, Zhu Z, Li Q, Lu W. Electronic properties and field emission of carbon nanotube films treated by hydrogen plasma. Appl Phys A 2003;77:811-7.

[36] Horn A, Schenk A, Biener J, Winter B, Lutterloh C, Wittmann M, et al. $\mathrm{H}$ atom impact induced chemical erosion reaction at $\mathrm{C}: \mathrm{H}$ film surfaces. Chem Phys Lett 1994;231(2-3):193-8.

[37] Wittmann M, Küppers J. A model of hydrogen impact induced chemical erosion of carbon based on elementary reaction steps. J Nucl Mater 1996;227(3):186-94.

[38] Yasuda A, Kawase N, Banhart F, Mizutani W, Shimizu T, Tokumoto H. Formation mechanism of carbon-nanocapsules and -nanoparticles based on the in-situ observation. J Phys Chem B 2002;106(6):1247-51. 
[39] Teunissen W, de Groot FMF, Geus J, Stephan O, Tence M, Colliex C. The structure of carbon encapsulated NiFe nanoparticles. J Catal 2001;204(1):169-74.

[40] Saito Y, Okuda M, Yoshikawa T, Kasuya A, Nishina Y. Correlation between volatility of rare-earth metals and encapsulation of their carbides in carbon nanocapsules. J Phys Chem 1994;98(27):6696-8.

[41] Ferro Y, Marinelli F, Allouche A. Density functional theory investigation of $\mathrm{H}$ adsorption and $\mathrm{H}_{2}$ recombination on the basal plane and in the bulk of graphite: connection between slab and cluster model. J Chem Phys 2002;116(18):8124-31.

[42] Ferro Y, Marinelli F, Allouche A. Density functional theory investigation of the diffusion and recombination of $\mathrm{H}$ on a graphite surface. Chem Phys Lett 2003;368(5-6):609-15.

[43] Cavell RG, Kowalczyk SP, Ley L, Pollak RA, Mills B, Shirley DA, et al. X-ray photoemission cross-section modulation in diamond, silicon, germanium, methane, silane, and germane. Phys Rev B 1973;7:5313-6. 